American J. of Engineering and Applied Sciences 2 (1): 8-16, 2009

ISSN 1941-7020

(C) 2009 Science Publications

\title{
Optimal Bidding Strategies for Generation Companies in a Day-Ahead Electricity Market with Risk Management Taken into Account
}

\author{
Azmi Saleh, Takao Tsuji and Tsutomu Oyama \\ Department of Electrical and Computer Engineering, Yokohama National University, \\ 79-5 Tokiwa-dai, Hodogaya-ku, Yokohama 240-8501, Japan
}

\begin{abstract}
Problem statement: In a competitive electricity market with limited number of producers, Generation Companies (Gencos) is facing an oligopoly market rather than a perfect competition. Under oligopoly market environment, each Genco may increase its own profit through a favorable bidding strategy. The objective of a Genco is to maximize its profit and minimize the associated risk. In order to achieve this goal, it is necessary and important for the Genco to make optimal bidding strategies with risk management before bidding into spot market to get an expected high profit, since spot prices are substantially volatile. This study propose a method to build optimal bidding strategies in a dayahead electricity market with incomplete information and considering both risk management and unit commitment. Approach: The proposed methodology employs the Monte Carlo simulation for modeling a risk management and a strategic behavior of rival. A probability density function (pdf), Value at Risk (VaR) and Monte Carlo simulation used to build optimal bidding strategies for a Genco. Results: The result of the proposed method shows that a Genco can build optimal bidding strategies to maximize expected total profit considering unit commitment and risk management. The Genco controls the risk by setting the confidence level. If the Genco increase the confidence level, the expected total VaR of profit decrease. Conclusions/Recommendations: The proposed method for building optimal bidding strategies in a day-ahead electricity market to maximize expected total profit considering unit commitment and risk management is helpful for a Genco to make a decision to submit bidding to the Independent System Operator (ISO).
\end{abstract}

Key words: Electricity market, bidding strategies, day- ahead electricity market, risk management, unit commitment, monte carlo

\section{INTRODUCTION}

Deregulation and reforming in the electricity market have created a competitive open market environment. Under the deregulated environment, the Genco operate own generating resources independently according their individual profits. The objective of a Genco is to max its profit and min the associated risk. In order to achieve this goal, its necessary and important for the Genco to make optimal bidding strategies with risk management before bidding into a spot market to get an expected high profit, since spot prices are substantially volatile.

The day-ahead electricity market is cleared on an hourly basis. The supply curve is built up for each hour considering the selling bids ordered by increasing prices and also a demand curve is built up considering the buying bids ordered by decreasing prices. The intersection of the supply curves and demand curves determines the selling and buying bids that are accepted. The hourly market price is the price of the last accepted selling bid. This process results in a uniform price for every hour.

A Unit commitment becomes responsible for each Genco and difficult for small Genco have one generation or small generation capacity. In order to build optimal bidding strategies with risk management, a Genco should consider a unit commitment with constrains in time periods (for example minimum up and down time, start-up and shut-down cost) for possibilities to get discontinuous dispatch that could reduce expected total profits.

In perfectly competitive electricity market, the optimal bidding strategies for a Genco is to bid its marginal operation cost. However, the emerging electricity markets are not perfectly competitive due to

Corresponding Author: Azmi Saleh, Department of Electrical and Computer Engineering, Yokohama National University, 79-5 Tokiwa-dai, Hodogaya-ku, Yokohama 240-8501, Japan Tel: +81-45-339-4126, Fax: +81-45-338-1157, E-mail: azmi2009@gmail.com 
special features, such as large investment size and economy of scale in the generation sector and therefore more akin to oligopoly. In an oligopoly electricity market, Genco could exercise strategic bidding to maximize own profit. The problem of how to develop optimal bidding strategies for competitive Genco in the electricity market was addressed for the first time ${ }^{[1]}$.

Many strategic bidding models have been reported in recent years, which can be grouped into three main categories as follows: (i) estimating the Market Clearing Price (MCP): Bid price is slightly lower than the estimated price ${ }^{[2,3]}$. (ii) game theories: base either on benefit matrix or imperfectly competitive game model $^{[4,6]}$. (iii) estimating the bidding behaviors of rivals: usually based on probabilistic method ${ }^{[7,8]}$. All strategic bidding models are without associated risks taken into account.

The first category is simple in principle. Based on the estimation of the MCP, the Genco determine its bidding strategies by offering in a price cheaper than the MCP. This method is based on an implicit assumption that the own bid will not influence the MCP. The game theory is applied in the second category. The bidding strategies have to be represented as discrete quantities such as "bidding high", "bidding medium" and "bidding low" in order to make problem simple. However, in realistic situation, bidding strategies can be continues quantities. The probabilistic method is applied in the third category. Based on historical data, the Genco can estimate bidding strategies of rivals. The Genco determine its bidding strategies based on the estimation of bidding of rivals. This method is assumed to be more practical in electricity market. Therefore it is used in this paper to build optimal bidding strategies.

This study proposes a method to build optimal bidding strategies in a day-ahead electricity market with incomplete information and considering both risk management and unit commitment. A probability density function (pdf) for bidding behaviors of rivals is considered to model the uncertainty in the rival behavior. The proposed methodology employs the monte carlo simulation for solving stochastic optimization. The risk management in uncertainty of rival behavior is analyzed using Value at Risk (VaR). The numerical test result of a simulated electricity market with four Genco used to demonstrate the essential features of the developed model and method.

\section{MATERIALS AND METHODS}

Market Structure: In the pool-based electricity market, every Genco submits a bidding price function to the Independent System Operator (ISO) for every hour of the planning horizon. The ISO uses the bidding price function and forecasting demand to determine the Market Clearing Price (MCP) and hourly generation outputs by maximizing the total surplus of generators and consumers. Assume that each Genco is required to submit linear bidding price function $\alpha_{j}+\beta j P_{j}$, where $P_{j}$ is the generation output and $\alpha_{\mathrm{j}}$ and $\beta_{\mathrm{j}}$ are bidding coefficient of bidding price function. The ISO determine the MCP and the hourly generation outputs each Genco using formulation as:

$$
\begin{aligned}
& R=\left[Q_{0}+\sum_{j=1}^{n} \frac{\alpha_{j}}{\beta_{j}}\right] /\left[\sum_{j=1}^{n} \frac{1}{\beta_{j}}\right] \\
& P_{j}=\frac{R-\alpha_{j}}{\beta_{j}}
\end{aligned}
$$

Subject to:

$$
\begin{aligned}
& \sum_{j=1}^{N} P_{j}=Q \\
& P_{j, \text { min }} \leq P_{j} \leq P_{j, \text { max }}
\end{aligned}
$$

Where:

$\mathrm{R}=$ The marginal clearing price

$\mathrm{Q}=$ The pool load forecasted

$P_{j}=$ The generation output of the jth Genco

When the solution set from (2) violates the generation outputs limit (4), it modified based on these constraints. When $\mathrm{P}_{j}$ is larger than upper limit constraints $P_{j, \max }, P_{j}$ should be set to $P_{j, \max }$. When $P_{j}$ is smaller than lower limit constraints $P_{j, \min }, P_{j}$ should be set to zero.

The profit function of jth Genco is defined by the difference between the total revenue and the total production cost as:

$\pi_{\mathrm{j}}=\mathrm{R} . \mathrm{P}_{\mathrm{j}}-\mathrm{C}\left(\mathrm{P}_{\mathrm{j}}\right)$

Subject to: (1-4)

Where:

$\pi_{\mathrm{j}} \quad=$ The profit of jth Genco

$\mathrm{C}_{\mathrm{j}}()=$. The production cost function of the $\mathrm{jth}$ Genco

The production cost function of the jth Genco is assuming a quadratic function as: 
$\mathrm{C}_{\mathrm{j}}\left(\mathrm{P}_{\mathrm{j}}\right)=\mathrm{a}_{\mathrm{j}}+\mathrm{b}_{\mathrm{j}} \cdot \mathrm{P}_{\mathrm{j}}+\mathrm{c}_{\mathrm{j}} \cdot \mathrm{P}_{\mathrm{j}}^{2}$

where, $a_{j}, b_{j}$ and $c_{j}$ is the coefficients of production cost.

The problem of building optimal bidding strategies for the ith Genco is determined $\alpha_{i}$ and $\beta_{i}$ so as to max profit as:

$\max \pi_{i}\left(\alpha_{i}, \beta_{i}, P_{i}\right)=\left(\alpha_{i}+\beta_{i} \cdot P_{i}\right) P_{i}-C_{i}\left(P_{i}\right)$

Subject to: (1-4)

To solve Eq. 7, the ith Genco need data of bidding coefficients of rivals. Because the bidding coefficients of rivals are confidential, the ith Genco could be estimated based on historical bidding data. The problem of ith Genco to estimating the bidding coefficients.

Estimating opponents unknown information: Generally, the Gencos do not have access to complete information of their opponent, so it is necessary for a Genco to estimate opponents' unknown information. It is assumed that the past data of bidding coefficients are available. The jth Genco can determine mean and standard deviations of bidding coefficients based on historical data. Suppose that the data of bidding coefficients are normally random variables with the following probability density function (pdf) as:

$\operatorname{pdf}\left(\mathrm{x}_{\mathrm{i}}\right)=\frac{1}{\sqrt{2 \pi \sigma_{\mathrm{i}}}} \cdot \exp \left(-\frac{\left(\mathrm{x}_{\mathrm{i}}-\mu_{\mathrm{i}}\right)^{2}}{2 \cdot \sigma_{\mathrm{i}}^{2}}\right)$

Where:

$\mu_{\mathrm{I}}=$ The mean values

$\sigma_{\mathrm{I}}=$ The standard deviations

The data of bidding coefficients have two values $\alpha_{j}$ and $\beta_{\mathrm{j}}$ (the intercept and slope) of bidding price function, respectively. The pdf function with two variables that represent the joint distribution of $\alpha_{j}{ }^{(t)}$ and $\beta_{\mathrm{j}}^{(\mathrm{t})}(\mathrm{j}=1,2, \ldots, \mathrm{n}, \mathrm{j} \neq \mathrm{i} ; \mathrm{t}=1,2, \ldots, 24)$ can be formulated as:

$$
\begin{aligned}
& \operatorname{pdf}_{\mathrm{i}}^{(\mathrm{t})}\left(\alpha_{\mathrm{j}}^{(\mathrm{t})}, \beta_{\mathrm{j}}^{(\mathrm{t})}\right)=\frac{1}{2 \pi \sigma_{\mathrm{j}, \mathrm{t}}^{(\alpha)} \sigma_{\mathrm{j}, \mathrm{t}}^{(\beta)} \sqrt{1-\rho_{\mathrm{j}, \mathrm{t}}^{2}}} \\
& \operatorname{x} \exp \left\{-\frac{1}{2\left(1-\rho_{\mathrm{j}, \mathrm{t}}^{2}\right)}\left[\left(\frac{\alpha_{\mathrm{j}}^{(\mathrm{t})}-\mu_{\mathrm{j}, \mathrm{t}}^{(\alpha)}}{\sigma_{\mathrm{j}, \mathrm{t}}^{(\alpha)}}\right)^{2}\right.\right. \\
& \left.\left.-\frac{2 \rho_{\mathrm{j}, \mathrm{t}}\left(\alpha_{\mathrm{j}}^{(\mathrm{t})}-\mu_{\mathrm{j}, \mathrm{t}}^{(\alpha)}\right)\left(\beta_{\mathrm{j}}^{(\mathrm{t})}-\mu_{\mathrm{j}, \mathrm{t}}^{(\beta)}\right)}{\sigma_{\mathrm{j}, \mathrm{t}}^{(\alpha)} \sigma_{\mathrm{j}, \mathrm{t}}^{(\beta)}}+\left(\frac{\beta_{\mathrm{j}}^{(\mathrm{t})}-\mu_{\mathrm{j}, \mathrm{t}}^{(\beta)}}{\sigma_{\mathrm{j}, \mathrm{t}}^{(\beta)}}\right)^{2}\right]\right\}
\end{aligned}
$$

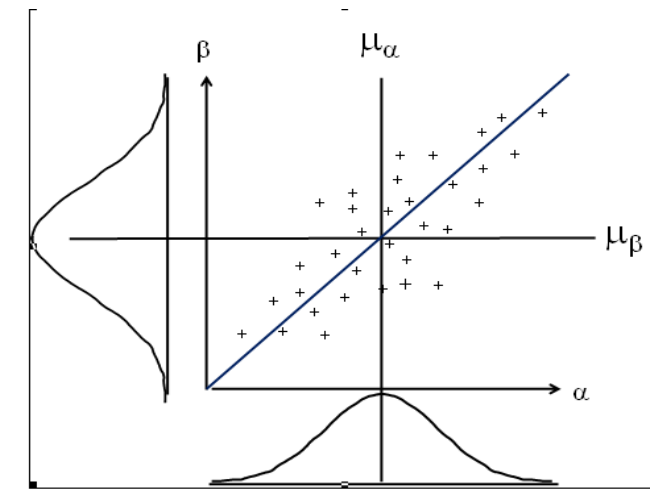

Fig. 1: The pdf of two variable $\alpha_{j}$ and $\beta_{j}$

This can be expressed in the compressed form as:

$$
\left(\alpha_{\mathrm{j}}^{\mathrm{t}}, \beta_{\mathrm{j}}^{\mathrm{t}}\right) \approx \mathrm{N}\left\{\left[\begin{array}{l}
\mu_{\mathrm{j}, \mathrm{t}}^{(\alpha)} \\
\mu_{\mathrm{j}, \mathrm{t}}^{(\beta)}
\end{array}\right],\left[\begin{array}{cc}
\left(\sigma_{\mathrm{j}, \mathrm{t}}^{(\alpha)}\right)^{2} & \rho_{\mathrm{j}} \cdot \sigma_{\mathrm{j}, \mathrm{t}}^{(\alpha)} \cdot \sigma_{\mathrm{j}, \mathrm{t}}^{(\beta)} \\
\rho_{\mathrm{j}} \cdot \sigma_{\mathrm{j}, \mathrm{t}}^{(\alpha)} \cdot \sigma_{\mathrm{j}, \mathrm{t}}^{(\beta)} & \left(\sigma_{\mathrm{j}, \mathrm{t}}^{(\beta)}\right)^{2}
\end{array}\right]\right\}
$$

Where:

$\rho_{\mathrm{j}} \quad=$ The correlation coefficient between $\alpha_{\mathrm{j}}$ and $\beta_{\mathrm{j}}$

$\mu_{\mathrm{j}}^{(\alpha)}, \mu_{\mathrm{j}}^{(\beta)}=$ The mean values

$\sigma_{j}^{(\alpha)}, \sigma_{j}^{(\beta)}=$ The standard deviations

The correlation coefficient is a number among -1 and 1. If there is no relation of two variables, the correlation coefficient is 0 . The perfect relations of two variables, the correlation coefficient is 1 or -1 . The two variables that represent the joint distribution of bidding coefficients can be visualized in Fig. 1.

Based on estimation of bidding coefficients, the ith Genco can determine $\alpha_{i}(t)$ and $\beta_{i}(t)(t=1,2, \ldots, 24)$ so as to maximize profit using Eq. 8. The optimal bidding problem became a stochastic problem.

Optimal bidding strategies in a day-ahead electricity market: The problem of developing bidding strategies for ith Genco in a day-ahead energy market can be formulated as maximization of total profit during $24 \mathrm{~h}$ as:

$$
\max \Omega=\sum_{\mathrm{t}=1}^{24}\left[\pi_{\mathrm{i}}^{(\mathrm{t})}-\mathrm{ST}_{\mathrm{i}}^{(\mathrm{t})}\left(1-\mathrm{u}_{\mathrm{t}-1}\right)\right] \mathrm{u}_{\mathrm{t}}
$$

Subject to:

$$
\mathrm{u}_{\mathrm{t}}= \begin{cases}1 & , \text { if } \mathrm{T}_{\text {on }}>\mathrm{T}_{\text {up }} \\ 0 & \text {, if } \mathrm{T}_{\text {off }}>\mathrm{T}_{\text {down }} \\ 0 \text { or } 1 & , \text { otherwise }\end{cases}
$$


Where:

ST $=$ The start-up cost

$\mathrm{u}_{\mathrm{t}}=$ The status of the ith Genco (1: operation, 0: down)

$\mathrm{T}_{\text {on }}=$ On time duration of the ith Genco

$\mathrm{T}_{\text {off }}=$ Off time duration of the ith Genco

$\mathrm{T}_{\text {up }}=$ Minimum up time

$\mathrm{T}_{\text {down }}=$ Minimum down time

When an ith Genco is in operation, it cannot shut down before a min up time period is met. On the other hand, when an ith Genco is in shut down, it cannot start up again before a min down time have passed. If min up time and min down time period have passed, the status of the ith Genco can set to 1 or 0 as to max total profit.

To solve Eq. 11 directly is difficult and should be solved separately as follow:

Step 1: Developing the bidding strategies and the status (ut) of the ith Genco for each hour of the schedule day, separately, using Eq. 1. If the ith Genco gets dispatch from ISO, set value of ut to 1 , otherwise, set to 0 (zero).

Step 2: Checking the status of the ith Genco with the unit commitment constraint. If the unit commitment constraint is satisfied, then these strategies are optimal for a day-ahead market and the ith Genco should remain in operation for the whole day and the procedure is completed here. Otherwise, go ahead to step 3 to update status for ith Genco.

Step 3: Determining the status for ith Genco to satisfy the unit commitment constraint using dynamic programming to maximize total profit during $24 \mathrm{~h}$. If ith Genco should be in operation because of the commitment constraint (due to constraints of minimum up time), update bidding coefficients and reduce bidding offer so that ith Genco can obtain dispatch from ISO.

The dynamic programming represents a multi stage decision problem as a sequence of single decision problems. The advantage of dynamic programming is its ability to maintain solution feasibility, unlike priority list method. Dynamic programming builds and evaluates the complete decision tree to optimize the problem.

The two possible states for ith Genco $\left(u_{t}=0\right.$ or 1$)$ problem can be solved using forward dynamic programming algorithm to run forward in time from initial hour to the final hour. The initial conditions are easily specified and the computations can go forward in time as long as required.
The proposed solution method: In order to solve the problem of building optimal bidding strategies for ith Genco in a day-ahead electricity market, first building optimal bidding strategies for each hour of the schedule using Eq. 7. Secondly is determining the unit status of ith Genco that satisfied unit commitment constraints using forward dynamic programming algorithm. The ith Genco is estimating the bidding coefficients based on pdf to model the uncertainty in the rival behavior. In this paper a Monte Carlo method is considered to deal with the aforementioned uncertainties.

The Monte Carlo method is a numerical simulation procedure applied to problem involving random variables with kwon or assumed probability distributions. It consists in repeating a deterministic simulation process, using in each simulation a particular set of values for the random variables that generated according to the corresponding probability distributions.

The basic procedure in Monte Carlo method is first is generating random samplings. The random samplings of two bidding coefficients from each rival according to their probability density function (pdf). Secondly is solving the optimization problem in Eq. 7 with all the bidding coefficients from rival participants as fixed constant numbers in Monte Carlo simulation iteration. Finally is calculation the statistic parameters such as the expectation value and standard deviation of the profit.

In order to solve the maximizing profit problem of the ith Genco, the two coefficients $\alpha_{i}(t)$ and $\beta_{i}(t)$, cannot be selected independently. The ith Genco can fix one and then determine the other by using an optimization procedure. In this work, the lagrangian relaxation method is used for this purpose. It is assumed that the ith Genco fixes bidding coefficients of $\alpha_{i}(t)$ and determine the bidding coefficients of $\beta_{i}(t)$. After all number of simulations is done, the expectation value of $\beta_{\mathrm{i}}(\mathrm{t})$ is adopted as the optimal bidding strategies of ith Genco.

Optimization based lagrangian relaxation method: The problem of building the optimal bidding strategies for ith Genco as Eq. 7 could be expressed minimizing production cost as:

$\min \pi_{\mathrm{i}}\left(\alpha_{\mathrm{i}}, \beta_{\mathrm{i}}, \mathrm{P}_{\mathrm{i}}\right)=\mathrm{C}_{\mathrm{i}}\left(\mathrm{P}_{\mathrm{i}}\right)-\left(\alpha_{\mathrm{i}}+\beta_{\mathrm{i}} \cdot \mathrm{P}_{\mathrm{i}}\right) \mathrm{P}_{\mathrm{i}}$

Subject to: (1-3)

Denote $\mathrm{u}=\mathrm{Q}_{0}+\sum_{\mathrm{j} \neq \mathrm{i}} \frac{\alpha_{\mathrm{j}}}{\beta_{\mathrm{j}}}$ and $\mathrm{v}=\sum_{\mathrm{j} \neq \mathrm{i}} \frac{1}{\beta_{\mathrm{j}}}$. Eq. 1 and 2 could be expressed as: 
Am. J. Engg. \& Applied Sci., 2 (1): 8-16, 2009

$\mathrm{R}=\frac{\alpha_{i}+\mathrm{u} \beta_{\mathrm{i}}}{\mathrm{v} \beta_{\mathrm{i}}+1}$

$P_{i}=\frac{u-\alpha_{i} v}{v \beta_{i}+1}$

Equation 13 could be solved through the generalized Lagrange multiplier method as:

$\mathrm{L}\left(\alpha_{\mathrm{i}}, \beta_{\mathrm{i}}, \mathrm{P}_{\mathrm{i}}, \lambda\right)=\mathrm{C}_{\mathrm{i}}\left(\mathrm{P}_{\mathrm{i}}\right)-\left(\alpha_{\mathrm{i}}+\beta_{\mathrm{i}} \cdot \mathrm{P}_{\mathrm{i}}\right) \mathrm{P}_{\mathrm{i}}$

$-\lambda\left(\mathrm{u}-\alpha_{\mathrm{i}} \mathrm{v}-\mathrm{P}_{\mathrm{i}}\left(\mathrm{v} \beta_{\mathrm{i}}+1\right)\right)$

The optimal solution of Eq. 16 with applying Kuhn $=$ Tucker conditions, could be obtained with assume $\alpha_{i}=b_{i}$ are:

$\beta_{i}=\frac{\left(2 c_{i} v+1\right) b_{i}-2 c_{i} u-u / v}{v b_{i}-u}$

Subject to:

$$
\mathrm{P}_{\mathrm{i}, \min } \leq \mathrm{P}_{\mathrm{i}} \leq \mathrm{P}_{\mathrm{i}, \max }
$$

When $P_{i}$ is less than $P_{i, m i n}$, update $\beta_{i}$ using the formula as:

$\beta_{i}=\frac{u-b_{i} v-P_{i, \min }}{v \cdot P_{i, \min }}$

When $\mathrm{Pi}$ is greater than $\mathrm{P}_{\mathrm{i}, \max }$, update $\beta_{\mathrm{i}}$ using formula (19) with replace $\mathrm{P}_{\mathrm{i} \text {,min }}$ with $\mathrm{P}_{\mathrm{i}, \max }$.

Risk consideration: To this point the problem of building the optimal bidding strategies without

considering risk. However, this concept is an important subject from Genco's viewpoint. Method for handling the risk is introduced. Value at Risk (VaR) is an estimate that shows how much a portfolio could lose due to market movements at a particular time horizon and for a given probability of occurrence. The given probability is called a confidence level, which represents the level of certainty of VaR.

In this study, the VaR is defined as the expected minimum profit of a portfolio over a target within a given confidence interval. The confidence level depends on the extent of the Genco's risk-aversion. Normally, a Genco with moderate risk-aversion adopts 95\% confidence level; a more risk-averse Genco may require $99 \%$ confidence level and a less risk-averse Genco could use $92.5 \%$ confidence level.

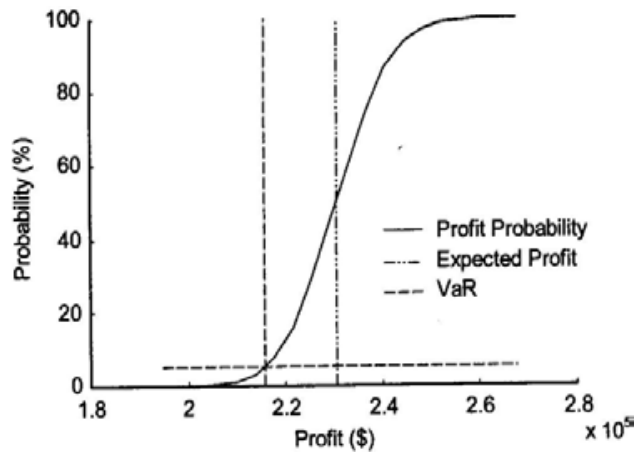

Fig. 2: Cumulative distribution function of profits

Monte Carlo simulation is used to calculate the $\mathrm{VaR}$ based on cumulative distribution function (cdf) of profit during the simulation process. For example, Fig. 2 show the cfd of the 1000 simulations. The profit corresponding with $(100-95 \%=5 \%)$ is $\mathrm{VaR}$, which is $\$ 2,15 \times 10^{5}$. According to Fig. 1 , there is a $95 \%$ probability that the actual profit will be larger than $\$ 2,15 \times 10^{5}$.

Expected profit corresponding with (100$50 \%=50 \%$ ) or without considering the risk is $\$ 2,30 \times 10^{5}$ which is a $50 \%$ probability that the actual profit will be larger than $\$ 2,30 \times 10^{5}$.

The Value at Risk (VaR) is calculated based on expected profit obtained by Monte Carlo method. The calculation of $\mathrm{VaR}$ is a three-step process:

Step 1: Aggregate the expected profit to form a distribution of expected profit.

Step 2: Create cumulative distribution function of expected profit from distribution of expected profit.

Step 3: Determine expected VaR of profit based on confidence level.

The building optimal bidding strategies in a dayahead electricity market with risk management taken into account is presented in flowchart in Fig. 3.

Two stages to building optimal bidding strategies:

Stage 1: Determining the optimal bidding strategies and expected profit each hour.

Stage 2: Determining the status for ith Genco to satisfy the unit commitment constraints.

In stage 1, creating the sampling of bidding coefficients rival every hour before determining optimal bidding parameter and expected profit each iteration (sampling). After the iteration finished, creating the cumulative probability distribution (cdf) of expected profit. Finally, a determining the optimal bidding parameter and expected $\mathrm{VaR}$ of profit based on cdf and confidence level. 
Am. J. Engg. \& Applied Sci., 2 (1): 8-16, 2009

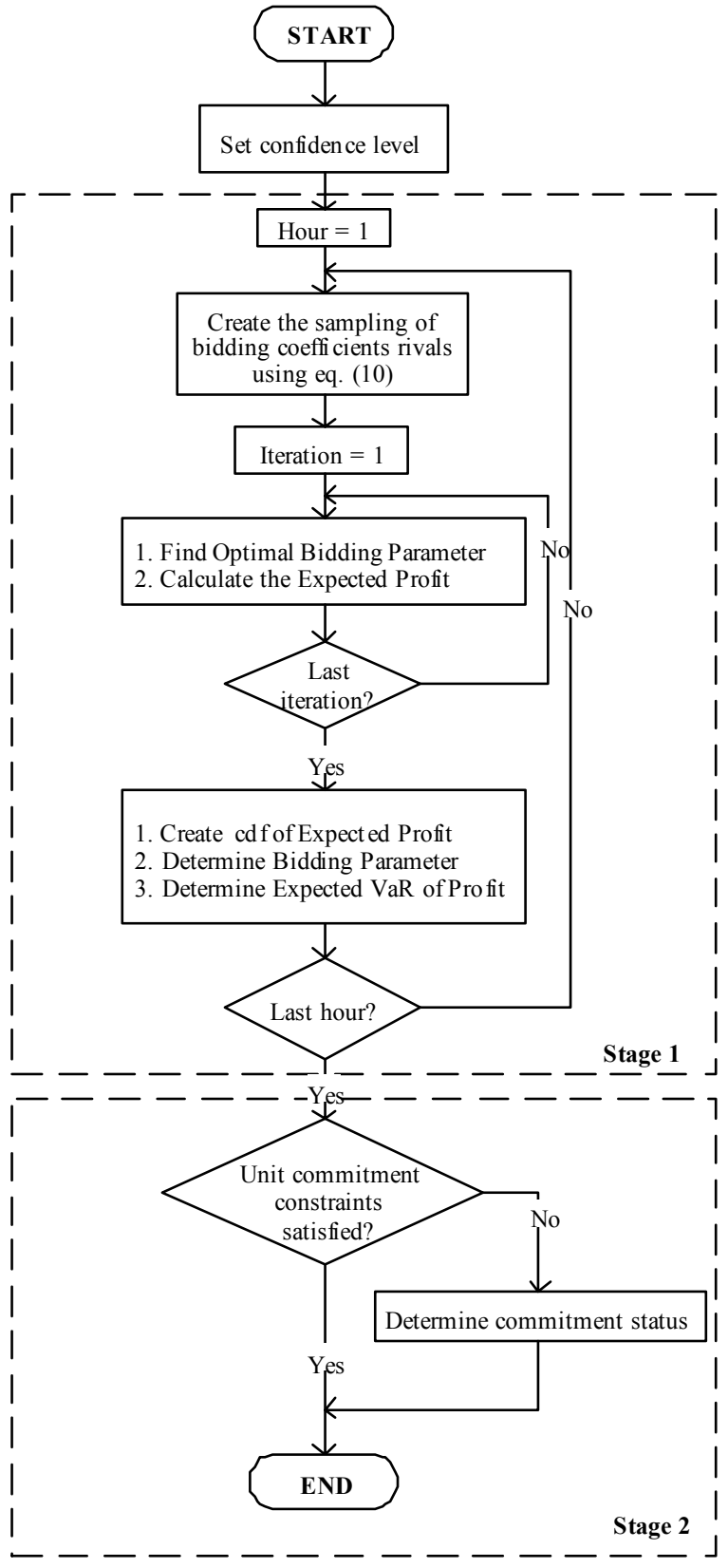

Fig. 3: Flow chart of the proposed method

In stage 2, check the unit commitment constraints. If satisfied, the calculation process is finish. If did not satisfied, a determining commitment status using dynamic programming.

\section{RESULTS}

The four Gencos is used to illustrate the results of application of the proposed method for building optimal bidding strategies in a day-ahead electricity market with considering risk management.
Table 1: Generation data

\begin{tabular}{llllll}
\hline Genco & $\mathrm{a}$ & $\mathrm{b}$ & $\mathrm{c}$ & $\operatorname{Pmin}(\mathrm{MW})$ & $\operatorname{Pmax}(\mathrm{MW})$ \\
\hline 1 & 94 & 9.4 & 0.0094 & 50 & 250 \\
2 & 96 & 9.6 & 0.0096 & 50 & 250 \\
3 & 105 & 10.0 & 0.0120 & 50 & 250 \\
4 & 105 & 11.0 & 0.0130 & 50 & 250 \\
\hline
\end{tabular}

Table 2: Estimations of the rivals

\begin{tabular}{llllll}
\hline Genco & $\mu_{\mathrm{j}, \mathrm{t}}^{(\alpha)}$ & $\mu_{\mathrm{j}, \mathrm{t}}^{(\beta)}$ & $\sigma_{\mathrm{j}, \mathrm{t}}^{(\alpha)}$ & $\sigma_{\mathrm{j}, \mathrm{t}}^{(\beta)}$ & $\rho_{\mathrm{j}, \mathrm{t}}$ \\
\hline 1 & $1.1 \mathrm{bj}$ & $\mathrm{w}_{\mathrm{t}} \times 2.1 \mathrm{cj}$ & $0.0375 \mathrm{bj}$ & $0.0375 \mathrm{cj}$ & -0.1 \\
2 & $1.1 \mathrm{bj}$ & $\mathrm{w}_{\mathrm{t}} \times 2.1 \mathrm{cj}$ & $0.0375 \mathrm{bj}$ & $0.0375 \mathrm{cj}$ & -0.1 \\
3 & $1.0 \mathrm{bj}$ & $\mathrm{w}_{\mathrm{t}} \times 2.0 \mathrm{cj}$ & $0.0375 \mathrm{bj}$ & $0.0375 \mathrm{cj}$ & -0.1 \\
\hline \multicolumn{4}{l}{$\mathrm{w}_{\mathrm{t}}=1+0.3\left(\mathrm{Q}-\mathrm{Q}_{\min }\right) /\left(\mathrm{Q}_{\max }-\mathrm{Q}_{\min }\right)$}
\end{tabular}

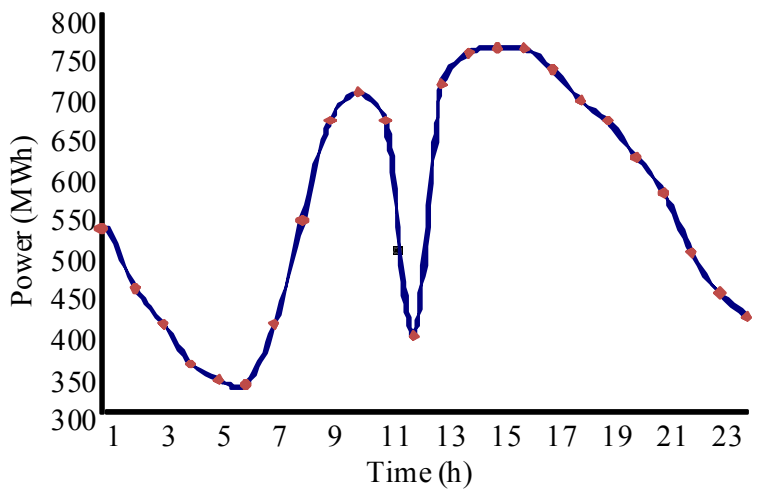

Fig. 4: Hourly loads

The production cost function of the jth Genco is $\mathrm{C}_{\mathrm{j}}\left(\mathrm{P}_{\mathrm{j}}\right)=\mathrm{a}_{\mathrm{j}}+\mathrm{b}_{\mathrm{j}} \cdot \mathrm{P}_{\mathrm{j}}+\mathrm{c}_{\mathrm{j}} \cdot \mathrm{P}_{\mathrm{j}}^{2}$. The coefficients of production cost function and output limits of all Gencos are shown in Table 1. Hourly loads in a day-ahead electricity market that ISO broadcast as shown in Fig. 4.

In the following case studies, we suppose that the fourth Genco in our subject research estimated joint normal distribution for the two bidding coefficients $\alpha_{i}{ }^{(t)}$ and $\beta_{i}{ }^{(t)}$ of the rivals'. The estimated parameters in the joint normal distribution for the rivals' as described in Eq. 5 are shown in Table 2. When sufficient bidding data from past bidding histories is available, these parameters can be estimated using stochastic methods.

Here, $Q_{\min }$ and $Q_{\max }$ are the minimum and maximum loads in the $24 \mathrm{~h}$ of a day-ahead electricity market, respectively and in this simulation $\mathrm{Q}_{\min }=335 \mathrm{MW}$ and $\mathrm{Q}_{\max }=755 \mathrm{MW}$. Hence, wt takes a value ranging from 1-1.3 and is a linearly increasing function of the system loads.

Optimal bidding without considering the risk: In first case, the fourth Genco building optimal bidding strategies in a day-ahead electricity market without considering the risk using the proposed method. 
Table 3: Optimal $\beta$ and expected profit without considering unit commitment constraint

\begin{tabular}{|c|c|c|c|c|c|}
\hline $\mathrm{T}$ & $\beta_{\mathrm{i}}$ & $\begin{array}{l}\text { Expected } \\
\text { Profit (\$) }\end{array}$ & $\mathrm{T}$ & $\beta_{\mathrm{i}}$ & $\begin{array}{l}\text { Expected } \\
\text { Profit (\$) }\end{array}$ \\
\hline 1 & 0.0273 & 18.411 & 13 & 0.0305 & 207.011 \\
\hline 2 & - & - & 14 & 0.0310 & 264.162 \\
\hline 3 & - & - & 15 & 0.0313 & 273.061 \\
\hline 4 & - & - & 16 & 0.0312 & 271.710 \\
\hline 5 & - & - & 17 & 0.0309 & 235.394 \\
\hline 6 & - & - & 18 & 0.0301 & 180.101 \\
\hline 7 & - & - & 19 & 0.0295 & 149.086 \\
\hline 8 & 0.0276 & 26.162 & 20 & 0.0290 & 98.602 \\
\hline 9 & 0.0297 & 149.960 & 21 & 0.0282 & 55.376 \\
\hline 10 & 0.0304 & 195.187 & 22 & - & - \\
\hline 11 & 0.0298 & 148.688 & 23 & - & - \\
\hline 12 & - & - & 24 & - & - \\
\hline
\end{tabular}

Table 4: Optimal $\beta$ and expected profit with considering unit commitment constraint

\begin{tabular}{lllllc}
\hline & & Expected & & & Expected \\
$\mathrm{T}$ & $\beta_{\mathrm{i}}$ & Profit (\$) & $\mathrm{T}$ & $\beta_{\mathrm{i}}$ & Profit (\$) \\
\hline 1 & - & - & 13 & 0.0305 & 207.011 \\
2 & - & - & 14 & 0.0310 & 264.162 \\
3 & - & - & 15 & 0.0313 & 273.061 \\
4 & - & - & 16 & 0.0312 & 271.710 \\
5 & - & - & 17 & 0.0309 & 235.394 \\
6 & - & - & 18 & 0.0301 & 180.101 \\
7 & - & - & 19 & 0.0295 & 149.086 \\
8 & 0.0276 & 26.162 & 20 & 0.0290 & 98.602 \\
9 & 0.0297 & 149.960 & 21 & 0.0282 & 55.376 \\
10 & 0.0304 & 195.187 & 22 & - & - \\
11 & 0.0298 & 148.688 & 23 & - & - \\
12 & 0.0254 & -61.685 & 24 & - & - \\
Expected total profit (\$) & & & 2211.23 \\
\hline
\end{tabular}

In this case, the confidence level is setting with 0.5 or $50 \%$. The simulation results of bidding coefficients and expected hourly profit is shown in Table 3 .

From Table 3, the fourth Genco getting to discontinue dispatch and unit commitment constraint did not satisfy. The fourth Genco determined the commitment status using dynamic programming to make unit commitment constraint did not satisfy with assume initial condition for fourth Genco is off. Final result from the commitment status is shown in Table 4.

The expected profit distribution and cumulative distribution of expected profit during Monte Carlo simulation process at $1 \mathrm{~h}$ and 16 are shown in Fig. 5 and 6 , respectively. The marginal clearing price during $24 \mathrm{~h}$ is shown in Fig. 7.

Optimal bidding with consider the risk: In the second case, Gencos consider the risk for bidding optimal bidding strategies in a day-ahead electricity market with setting confidence level above $50 \%$. In this simulation, the fourth Genco setting value of a confidence level is $95 \%$ and $99 \%$, respectively. The simulation results of bidding coefficients and expected hourly profit is shown in Table 5 .

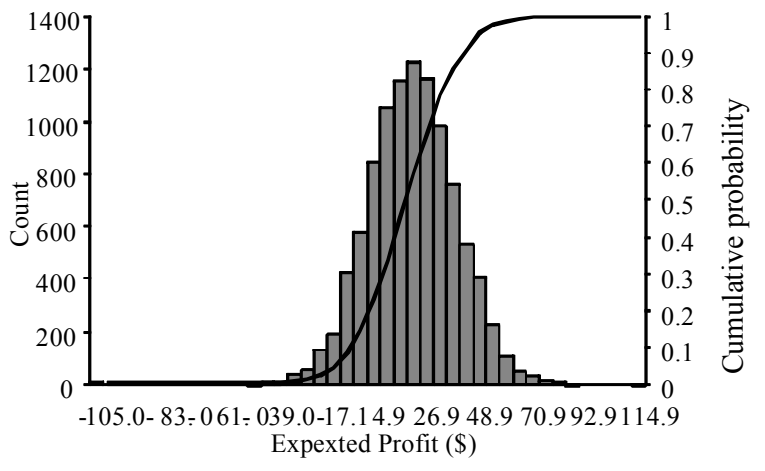

Fig. 5: Distribution and cumulative distribution of expected hourly profit at $1 \mathrm{~h}$

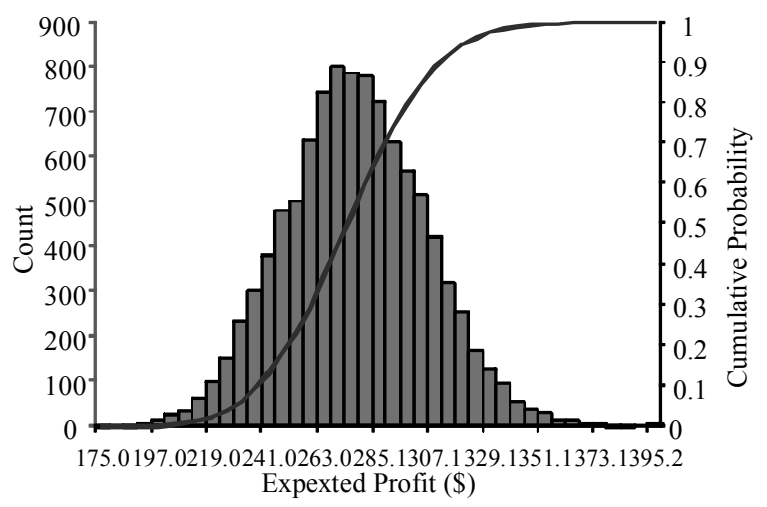

Fig. 6: Distribution and cumulative distribution of expected hourly profit at $16 \mathrm{~h}$

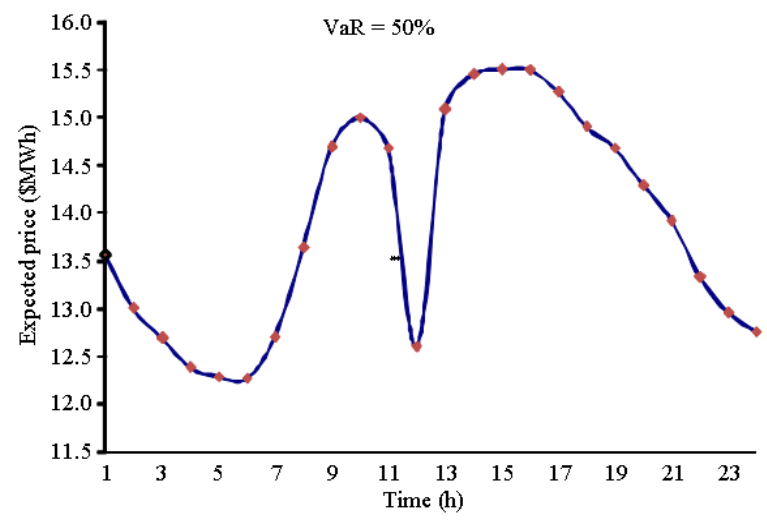

Fig. 7: The expected hourly marginal clearing price

From Table 5, the fourth Genco getting to discontinue dispatch and unit commitment constraint did not satisfy. The fourth Genco determined the commitment status using dynamic programming to make unit commitment constraint did not satisfy with assume initial condition for fourth Genco is off. Final result from the commitment status is shown in Table 6 . 
Table 5: Optimal $\beta$ and expected var of profit without considering unit commitment constraint

\begin{tabular}{|c|c|c|c|c|c|c|}
\hline \multirow[b]{3}{*}{$\mathrm{T}$} & \multicolumn{2}{|c|}{ Without Risk } & \multicolumn{2}{|c|}{$\mathrm{VaR}=95 \%$} & \multicolumn{2}{|c|}{$\operatorname{Var}=99 \%$} \\
\hline & Expected & & Expected & & Expected & \\
\hline & $\beta_{\mathrm{i}}$ & Profit (\$) & $\beta_{\mathrm{i}}$ & Profit (\$) & $\beta_{\mathrm{i}}$ & Profit (\$) \\
\hline 1 & 0.0273 & 18.411 & - & - & - & - \\
\hline 2 & - & - & - & - & - & - \\
\hline 3 & - & - & - & - & - & - \\
\hline 4 & - & - & - & - & - & - \\
\hline 5 & - & - & - & - & - & - \\
\hline 6 & - & - & - & - & - & - \\
\hline 7 & - & - & - & - & - & - \\
\hline 8 & 0.0276 & 26.162 & - & - & - & - \\
\hline 9 & 0.0297 & 149.960 & 0.0272 & 111.266 & 0.0260 & 96.358 \\
\hline 10 & 0.0304 & 195.187 & 0.0281 & 153.579 & 0.0272 & 137.514 \\
\hline 11 & 0.0298 & 148.688 & 0.0272 & 109.606 & 0.0263 & 95.432 \\
\hline 12 & - & - & - & - & - & - \\
\hline 13 & 0.0305 & 207.011 & 0.0282 & 165.411 & 0.0273 & 148.275 \\
\hline 14 & 0.0310 & 264.162 & 0.0289 & 219.348 & 0.0281 & 205.228 \\
\hline 15 & 0.0313 & 273.061 & 0.0292 & 228.586 & 0.0284 & 209.807 \\
\hline 16 & 0.0312 & 271.710 & 0.0291 & 227.898 & 0.0283 & 210.505 \\
\hline 17 & 0.0309 & 235.394 & 0.0286 & 191.533 & 0.0277 & 170.856 \\
\hline 18 & 0.0301 & 180.101 & 0.0279 & 140.134 & 0.0269 & 126.127 \\
\hline 19 & 0.0295 & 149.086 & 0.0269 & 109.281 & 0.0260 & 94.725 \\
\hline 20 & 0.0290 & 98.602 & 0.0264 & 64.569 & 0.0251 & 48.081 \\
\hline 21 & 0.0282 & 55.376 & 0.0252 & 22.193 & 0.0238 & 7.623 \\
\hline 22 & - & - & - & - & - & - \\
\hline 23 & - & - & - & - & - & - \\
\hline 24 & - & - & - & - & - & - \\
\hline
\end{tabular}

Table 6: Optimal $\beta$ and expected var of profit with considering unit commitment constraint

\begin{tabular}{|c|c|c|c|c|c|c|}
\hline \multirow[b]{3}{*}{$\mathrm{T}$} & \multicolumn{2}{|c|}{ Without risk } & \multicolumn{2}{|c|}{$\mathrm{VaR}=95 \%$} & \multicolumn{2}{|c|}{$\operatorname{Var}=99 \%$} \\
\hline & \multicolumn{2}{|c|}{ Expected } & \multicolumn{2}{|c|}{ Expected } & \multicolumn{2}{|c|}{ Expected } \\
\hline & $\beta_{\mathrm{i}}$ & Profit (\$) & $\beta_{\mathrm{i}}$ & Profit (\$) & $\beta_{\mathrm{i}}$ & Profit (\$) \\
\hline 1 & - & - & - & - & - & - \\
\hline 2 & - & - & - & - & - & - \\
\hline 3 & - & - & - & - & - & - \\
\hline 4 & - & - & - & - & - & - \\
\hline 5 & - & - & - & - & - & - \\
\hline 6 & - & - & - & - & - & - \\
\hline 7 & - & - & - & - & - & - \\
\hline 8 & 0.0276 & 26.162 & - & - & - & - \\
\hline 9 & 0.0297 & 149.960 & 0.0272 & 111.266 & 0.0260 & 96.358 \\
\hline 10 & 0.0304 & 195.187 & 0.0281 & 153.579 & 0.0272 & 137.514 \\
\hline 11 & 0.0298 & 148.688 & 0.0272 & 109.606 & 0.0263 & 95.432 \\
\hline 12 & 0.0254 & -61.685 & 0.0236 & -74.060 & 0.0228 & -80.466 \\
\hline 13 & 0.0305 & 207.011 & 0.0282 & 165.411 & 0.0273 & 148.275 \\
\hline 14 & 0.0310 & 264.162 & 0.0289 & 219.348 & 0.0281 & 205.228 \\
\hline 15 & 0.0313 & 273.061 & 0.0292 & 228.586 & 0.0284 & 209.807 \\
\hline 16 & 0.0312 & 271.710 & 0.0291 & 227.898 & 0.0283 & 210.505 \\
\hline 17 & 0.0309 & 235.394 & 0.0286 & 191.533 & 0.0277 & 170.856 \\
\hline 18 & 0.0301 & 180.101 & 0.0279 & 140.134 & 0.0269 & 126.127 \\
\hline 19 & 0.0295 & 149.086 & 0.0269 & 109.281 & 0.0260 & 94.725 \\
\hline 20 & 0.0290 & 98.602 & 0.0264 & 64.569 & 0.0251 & 48.081 \\
\hline 21 & 0.0282 & 55.376 & 0.0252 & 22.193 & 0.0238 & 7.623 \\
\hline 22 & - & - & - & - & - & - \\
\hline 23 & - & - & - & - & - & - \\
\hline 24 & - & - & - & - & - & - \\
\hline \multicolumn{2}{|c|}{ Total profit } & 2211.230 & & 1669.340 & & 1470.060 \\
\hline
\end{tabular}

The marginal clearing price during $24 \mathrm{~h}$ with a difference confidence level is shown in Fig. 8.

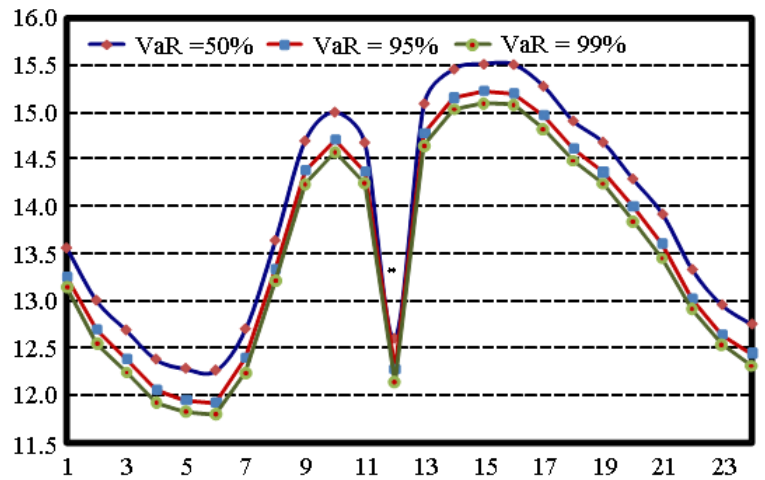

Fig. 8: The expected hourly marginal clearing price with difference confidence level

\section{DISCUSSION}

In Table 2, fourth Genco make estimation for two bidding coefficients $\alpha_{\mathrm{i}}(\mathrm{t})$ and $\beta_{\mathrm{i}}(\mathrm{t})$ of the rivals'. For the first rivals, the mean value of $\alpha_{1}(\mathrm{t})$ and $\beta_{1}(\mathrm{t})$ are $10 \%$ above bj and wt times of $2.1 \mathrm{xcj}$, respectively. Also, the standard deviations of $\alpha_{1}(t)$ and $\beta_{1}(t)$ are $0.0375 \times b 1$ and $0.0375 \mathrm{xc} 1$, respectively. The correlation coefficient among $\alpha_{1}(\mathrm{t})$ and $\beta_{1}(\mathrm{t})$ is -0.1 . The correlation is negative because when rivals decide to increase one of its two bidding coefficients, it will decrease rather than increase the other coefficient.

For example, in $1 \mathrm{~h}$ the mean value of $\alpha_{1}(\mathrm{t})$ and $\beta_{1}(t)$ are 10.34 and wtx 0.0188 or 0.0213 , respectively. The standard deviations of $\alpha_{1}(\mathrm{t})$ and $\beta_{1}(\mathrm{t})$ are 0.3525 and 0.0033 . The range value of $\alpha_{1}(\mathrm{t})$ and $\beta_{1}(\mathrm{t})$ are $[9.9875 ; 10.6925]$ and $[0.018 ; 0.0246]$

Optimal bidding without considering the risk: In Table 4, the fourth Genco did not submit offer during 1 until $7 \mathrm{~h}$ and during 22 until $24 \mathrm{~h}$. The fourth Genco still submit offer in $12 \mathrm{~h}$. to satisfy unit commitment constraint with negative expected profit is $-\$ 61.685$. The total expected profit of fourth Genco is $\$ 2211.23$.

In Fig. 5, the probability for fourth Genco getting profit $\$ 18.411$ or more is $50 \%$ and the probability getting negative profit is about $15 \%$. It means, the fourth Genco have been risk to getting profit negative in $1 \mathrm{~h}$.

In Fig. 6, the probability for fourth Genco getting hourly profit $\$ 271.71$ or more is $50 \%$ and the probability getting negative profit is $0 \%$. It means, the fourth Genco no risk to getting negative profits in $16 \mathrm{~h}$.

Optimal bidding with consider the risk: In Table 6, the fourth Genco with confidence level $95 \%$ and $99 \%$ did not submit offer during hour 1 until hour 8 and 
during 22 until $24 \mathrm{~h}$. The fourth Genco still submit offer in $12 \mathrm{~h}$ to satisfy unit commitment constraint with negative expected VaR of profit are $-\$ 64.685$ and $\$ 80.466$, respectively. The total expected VaR of profit are $\$ 1669.34$ and $\$ 1470.06$, respectively. In this case, increasing a confidence level only decreasing the expected profit.

\section{CONCLUSION}

In this research, bidding decisions problem in dayahead electricity market considering risk management and unit commitment is formulated from the Genco viewpoint. A stochastic optimization model is built for this purpose using Monte Carlo simulation and Lagrangian Relaxation and efficient for solving this problem. Simulation results of a numerical example have demonstrated the effect of a confidence level to the decision submits offer and expected total VaR of profit. In this case study only shown effect of confidence level to the expected total $\mathrm{VaR}$ of profit. If the Genco increased the confidence level, the expected total $\mathrm{VaR}$ of profit will decreased.

\section{REFERENCES}

1. David, A.K., 1993. Competitive bidding in electricity supply. IEE Proceeding of the Generation Transmission Distributiion., Sep. 1993, IEEE Xplore, USA., 140: 421-426. $\mathrm{http} / /$ ieeexplore.ieee.org/xpl/freeabs_all.jsp?arnum ber $=237910$.
2. Shangyou, H., 2000. A study of basic bidding strategy in clearing pricing auctions. IEEE Trans. Power Syst., 15: 975-980. DOI: 10.1109/59.871721.

3. Ferrero, R.W. and J.F. Rivera, 2002. Price-taker bidding strategy under price uncertainty, IEEE Trans. Power Syst., 17: 1081-1088. DOI: 10.1109/TPWRS.2002.804948.

4. Ferrero, R.W. and J.F. Rivera, 1998. Application of games with incomplete information for pricing electricity in deregulated power pools. IEEE Trans. Power Syst., 13: 184-189. http://ieeexplore.ieee. org/xpl/freeabs_all.jsp?arnumber $=651634$.

5. Gan, D., J. Wang and D.V. Bourcier, 2005. An auction game model for pool-baed electricity markets. Elect. Power Energ. Syst., 27: 480-487. DOI: 10.1016/j.ijepes.2005.06.001.

6. Kang, D.J., B.H. Kim and D. Hur, 2007. Suplier bidding strategy based on non-cooperative game theory concepts in single auction power pools. Elect. Power Energ. Syst., 77: 630-636. DOI: 10.1016/j.epsr.2006.05.012.

7. Fushuan, W. and A.K. David, 2001. Optimal bidding strategies and modeling of imperfect information among competitive generators. IEEE Trans. Power Syst., 16: 15-21. DOI: 10.1109/59.910776.

8. Shreshta, G.B. and L.K.S. Goel, 2001. Strategic bidding for minimum power output in the competitive power market. IEEE Trans. Power Syst., 16: 813-819. DOI: 10.1109/59.962431. 